\title{
12
}

\section{A cache of one-piece fishhooks from Pohara, Takaka, New Zealand}

\author{
Janet Davidson \\ Honorary Research Associate, Museum of New Zealand Te Papa Tongarewa, New Zealand \\ Janet.Davidson@University-of-Ngakuta.ac.nz \\ Foss Leach \\ Honorary Research Associate, Museum of New Zealand Te Papa Tongarewa, New Zealand
}

\section{Introduction}

More than 40 years ago, Atholl Anderson carried out his first major archaeological fieldwork in Tasman Bay, in the northwest of the South Island (Anderson 1966). This paper describes an important cache of fishhooks found recently near Takaka in Mohua (Golden Bay), immediately to the west of Tasman Bay. We offer the paper to Atholl in recognition of his pioneering archaeological work in Te Tau Ihu (the top of the South Island) and his life-long commitment to the study and practice of fishing. In his MA thesis in geography, Atholl acknowledged the help of Don Millar, who provided him with unpublished information. We also acknowledge the generous assistance of Don Millar during our present study.

In July 2002, W. Butler, a resident of Takaka, discovered the fishhooks while he was preparing a new climbing route on a limestone cliff at Pohara (Figure 1). The limestone scarp is in coastal scrub about $15 \mathrm{~m}$ back from the inner edge of the roadway (Figure 2). The formation is part of the late Oligocene-early Miocene Takaka Limestone, which is usually less than $100 \mathrm{~m}$ thick and regarded as 'platform facies'; in other words, it formed on a stable platform and includes shallowwater bioclastic limestone with a muddy micaceous component (Rattenbury et al. 1998). The limestone is relatively pure. An average analysis has 90 percent $\mathrm{CaCO}_{3}, 2.5$ percent $\mathrm{SiO}_{2}, 0.42$ percent $\mathrm{Al}_{2} \mathrm{O}_{3}$, and 1.68 percent $\mathrm{Fe}_{2} \mathrm{O}_{3}$ (K. Miller pers comm.). Although this rocky headland extends down to sea level, the marine environment in the vicinity and elsewhere in Golden Bay is dominated by sandy shorelines and the marine faunas associated with these.

The fishhooks were on a ledge about $400 \mathrm{~mm}$ long and $200 \mathrm{~mm}$ deep, and were covered by about $25 \mathrm{~mm}$ of lime dust. The limestone in this vicinity is horizontally bedded with numerous crevices, ledges and blocks, and the ledge where the hooks were found was only $2.5 \mathrm{~m}$ above the ground. Above the ledge is a high overhang, representing a suitable challenge for rock climbers. 


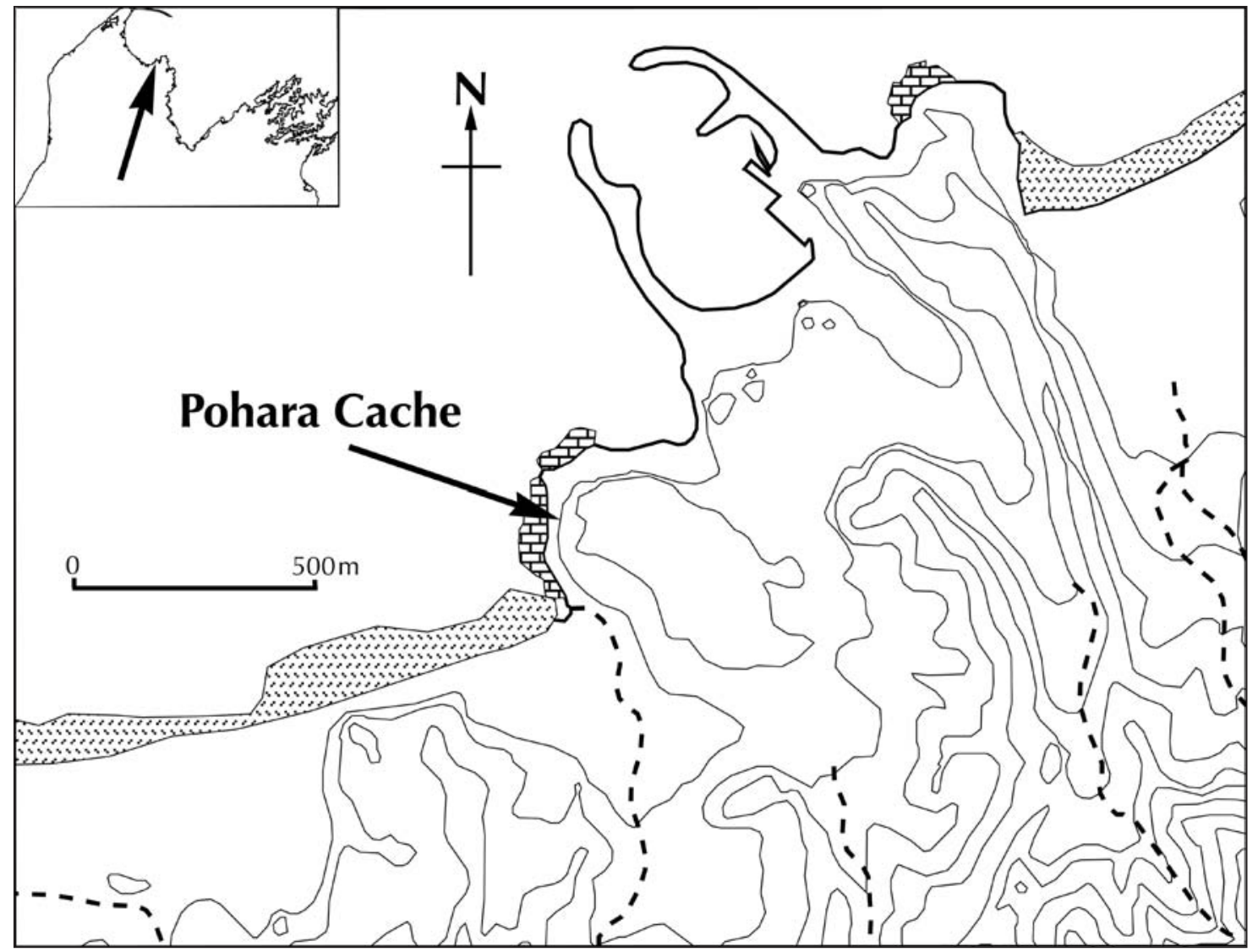

Figure 1. The Pohara fishhook cache was found on the eastern side of Mohua (Golden Bay) near Takaka.

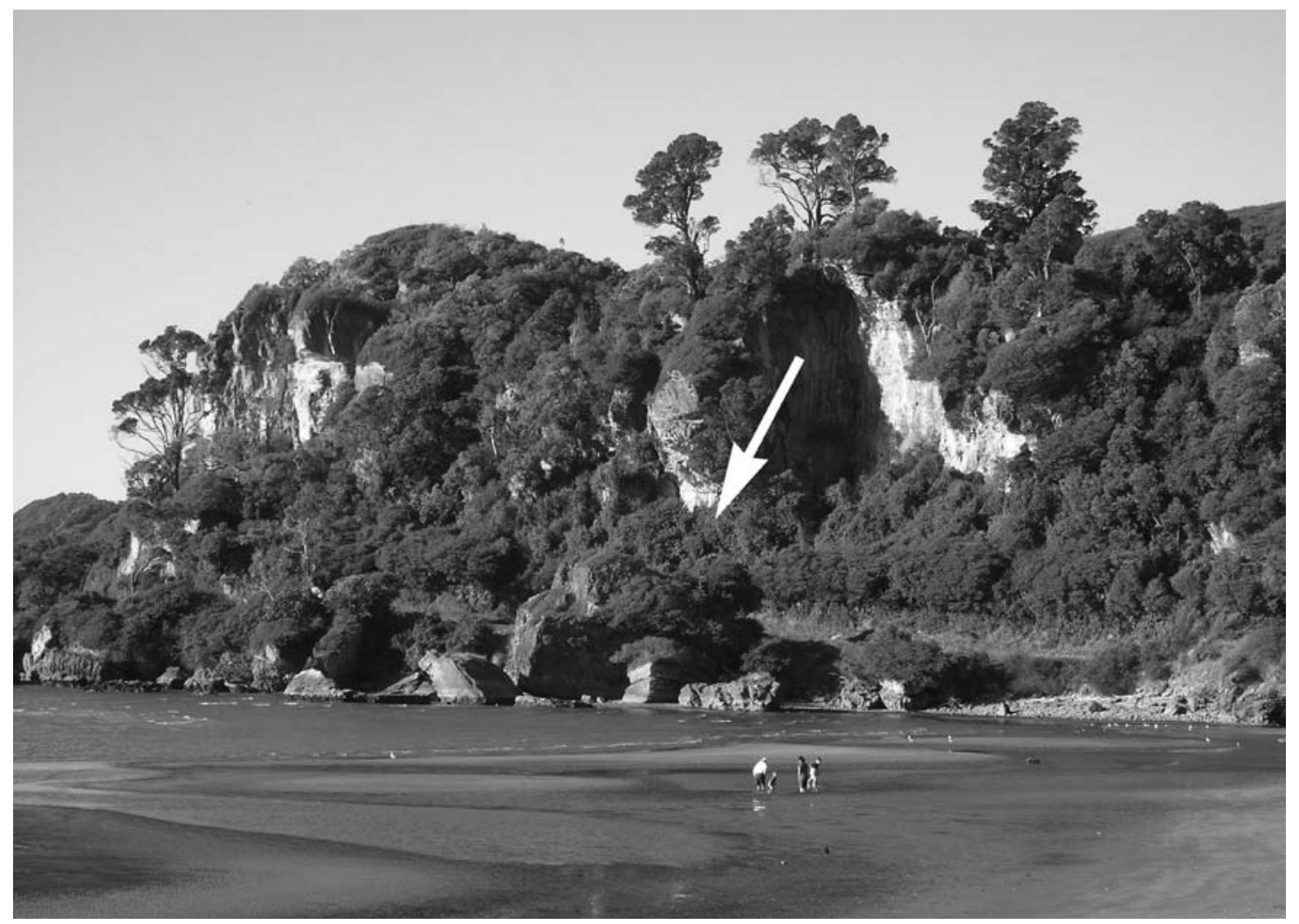

Figure 2. The limestone bluff where the fishhook cache was found (courtesy of Steve Bagley). 
There is no obvious evidence of midden or cooking debris at the base of the limestone cliff, but there is a substantial surface deposit of limestone that has eroded from the face, and there could be archaeological layers buried deeply below present ground level. The site number is N25/119.

Fifteen hooks were recovered and taken to the Nelson Provincial Museum. The Maori community at Takaka, Manawhenua ki Mohua, has taken an active interest in these hooks and a meeting was held at the museum to discuss their conservation and study. In April 2003, another meeting was held at the Onetahua marae at Pohara so more members of Manawhenua ki Mohua could see the hooks and decide what studies were appropriate. It was agreed a small fragment of the fibre should be taken for identification and radiocarbon dating.

\section{Description of the hooks}

The 15 hooks are beautifully finished and all are in an excellent state of preservation. Several have fragments of their original snood lashing. ${ }^{1}$ The fibre is very fragile and powders easily. The fact that these fibres are still present is no doubt due to the extremely dry limestone dust covering them on the ledge. The fragments of cordage are shown in Figure 3. Hook 8 has parts of the original lashing close by in unravelled form. Hook 13 has a considerable quantity of the original lashing still present at the top of the shank, but again partly unravelled. Hook 14 also has unravelled cordage at the top of the shank. Finally, Hook 15 has loose loops of the original lashing around the top of the shank. In addition to these pieces of cordage that were still loosely attached to the hooks, there are several separate pieces, which can also be seen in Figure 3. One piece is above Hook 12, another is below Hook 5, and the largest piece is a small coil of line to the right of Hook 5.

The most notable feature of these fragments of cordage is that almost all are rectangularsectioned pieces of unscutched strips of plant. The species has not been definitely identified yet. Rod Wallace, who examined the fibre under plain microscopy, is certain that it is not New Zealand flax (Phormium tenax). He suggests either pohuehue (Muehlenbeckia cf. complexia) or nikau (Rhopalostylis sapida). Scanning electron microscopy and micro-computed tomography by Catherine Smith and Debra Carr failed to identify the species. Goulding (1971) found very few references to fibre plants used for fishing gear. Strips of unscutched flax were commonly used by pre-European Maori for making fishing nets (Leach 2006:104ff.); a few accounts suggest that actual fishing lines were made of dressed flax fibres (Colenso 1875:265; Hiroa 1950:216; Best 1977:45). On most museum specimens of Maori bone and wooden fishhooks from the early European period, the snood lashing uses very fine fibre cordage, at least on the exterior. It is possible that in at least some cases, coarser lengths of unscutched strips are hidden inside this outer lashing. The snood lashing of the Pohara hooks appears rather crude, but this may not be so. These strips of untreated plant may have been deliberately chosen for use around the shank of the hook for extra strength, woven into the main two or three-ply cordage, and then covered with finer fibres.

\section{Hook shape}

The shape of the hooks is illustrated in Figure 4. All are close to U-shaped, with the point leg almost as long as the shank. The points of the hooks all curve downwards, in a form that appears similar to the barb on a European metal hook. Directly opposite the point in most cases there is a projection from the shank reminiscent of a shank barb on a European metal hook. When viewed together, these two projections, on the point leg and the shank, enclose a near 
symmetrical heart shape in the interior open space (see for example Figure 4 item 8). Entrance to this open space is smooth, rather like the entrance to an eel trap (hinaki), but once through the gap, there is little chance of escape. Of the four hooks without shank barbs, Hook 2 has a slight bulge and Hook 12 a slight protrusion on the inner side of the shank head, while in Hooks 3 and 6 the shank is smooth.

At the head or top of the shank leg there are projections that assist the binding of cord to the hook. These are rather variable in form.

Seven hooks have a small feature at the base of the U-shape. In Hooks 1, 2, 8 and 9, this takes the form of a simple notch. In Hooks 5, 12 and 14, there is a slight projection, rather than a notch. Some ethnographic specimens of Maori bone fishhooks with notches have fine lines attached. They are generally thought to have been used to tie bait on to the hook to prevent it coming off when fish bite it. The features on Hooks, 5, 12 and 14 could also have secured a bait string, as Hiroa (1957:327) suggested for a similar feature on some Hawaiian hooks. In one case (Hook 5), there are several notches towards the bottom of the point leg that might have served the same function. However, they might simply have been decorative features.

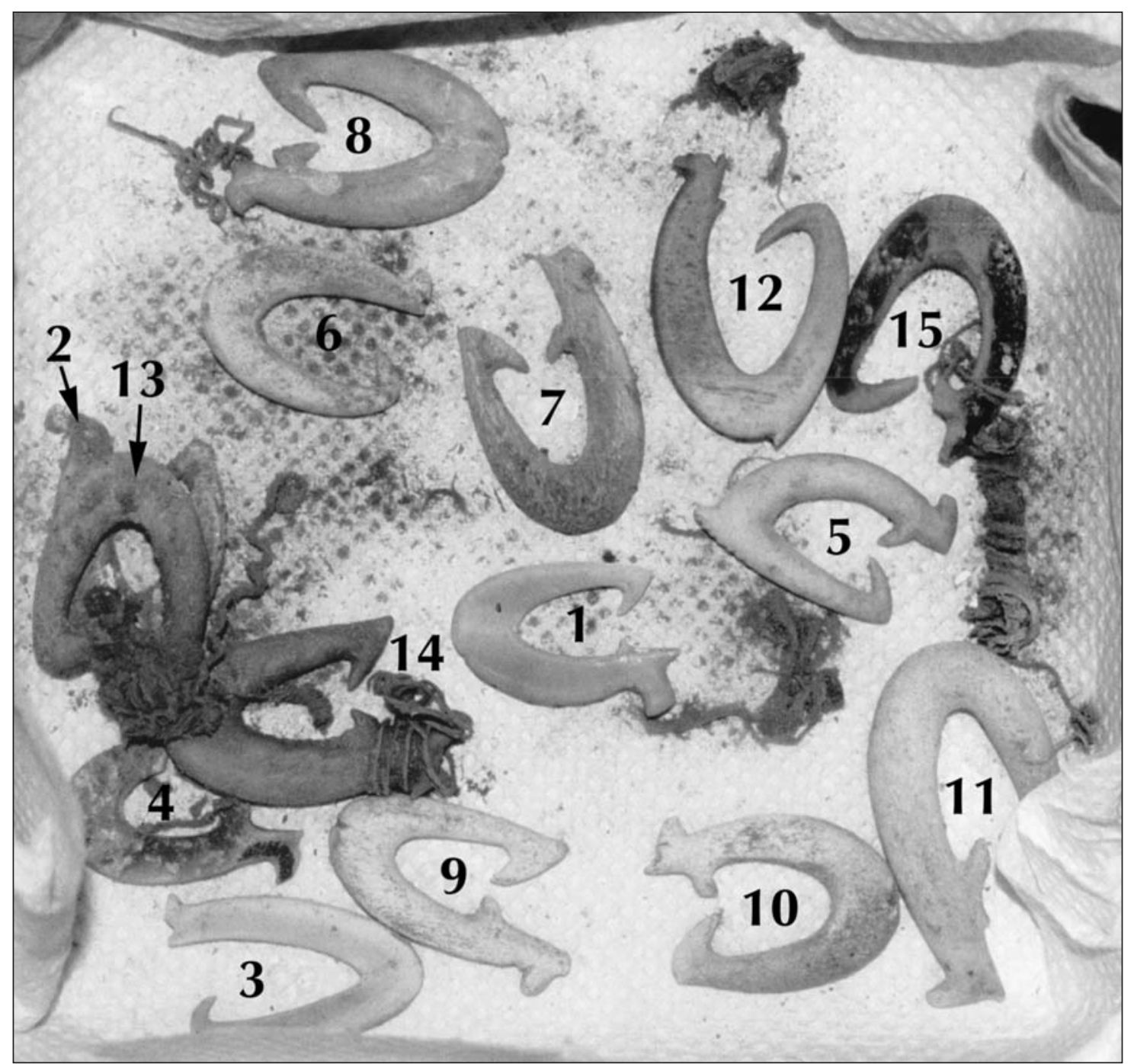

Figure 3. The hooks shortly after removal from the cleft, showing the remains of cordage (courtesy of Nelson Provincial Museum). 


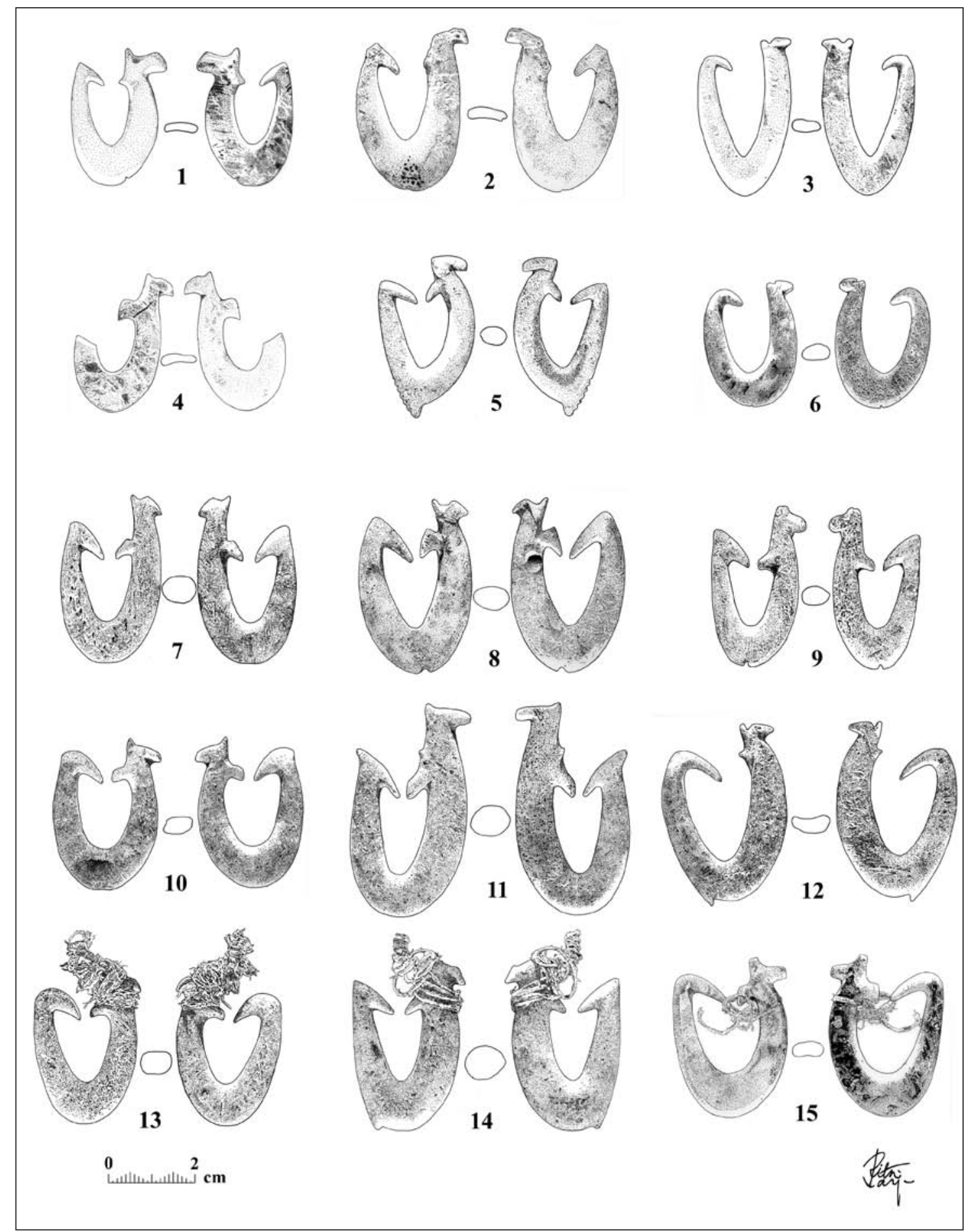

Figure 4. Details of the Pohara fishhooks (drawing by Rita Larje). 


\section{The point gap}

A striking feature of many of these hooks is the small gap between the point and the shank. This is documented below (Table 1). Hook 4 has a broken point, so the gap could not be measured. The height measurement is the overall height in $\mathrm{mm}$ at right angles to the base of each specimen, and the gap is the distance in mm between the point and the shank.

\section{Materials}

Identifying the species of plants or animals used for making artefacts is always very difficult. Unfortunately, very little research has been done in New Zealand to characterise the most common organic materials that may have been used by pre-European Maori. This can involve the use of scanning electron microscope for minute detail, and/or elemental characterisation with X-ray fluorescence analysis, and/or molecular characterisation with techniques such as infra-red or Raman spectroscopy. In the absence of such background research, hand specimen identifications are little better than guesswork.

With considerable reservations, therefore, some possible identifications are made here of the materials used for these hooks (Table 2). These are based on observations with low power binocular microscope and comparison with identified specimens of materials. Sea mammal bone, for example, has quite diagnostic features, such as a porous trabecular framework, compared with human lamellar bone, which is very dense.

Table 1. Pohara fishhook measurements. Overall hook height $(\mathrm{mm})$ and point gap $(\mathrm{mm})$.

\begin{tabular}{lll}
\hline \multicolumn{2}{l}{ Hooks with no shank barb } \\
\hline Hook \# & Height & Gap \\
\hline 2 & 38.0 & 5.5 \\
3 & 36.0 & 8.0 \\
6 & 30.5 & 6.7 \\
12 & 41.0 & 7.0 \\
\hline
\end{tabular}

\begin{tabular}{lll}
\hline \multicolumn{2}{l}{ Hooks with shank barb } \\
\hline Hook \# & Height & Gap \\
\hline 1 & 32.0 & 3.0 \\
4 & 34.0 & - \\
5 & 36.0 & 2.0 \\
7 & 40.0 & 2.9 \\
8 & 40.0 & 2.0 \\
9 & 38.0 & 2.0 \\
10 & 36.0 & 2.3 \\
11 & 50.0 & 1.9 \\
13 & 34.7 & 2.5 \\
14 & 40.0 & 2.7 \\
15 & 37.1 & 2.6 \\
\hline
\end{tabular}

\section{Radiocarbon dating}

A few of the loose threads were submitted for radiocarbon dating. These were teased apart and cleaned by washing in warm water, followed by consecutive treatments in hot solutions of acid, alkali, and acid. This ensured any limestone dust would be removed. The clean threads were then burnt in a sealed quartz tube at $900 \mathrm{C}$, which converted all organic material to carbon dioxide gas. The gas was then purified and converted to graphite for measurement in an accelerator mass spectrometer. A small sample was used for determination of ${ }^{13} \mathrm{C}$, which proved to be -27.2 percent, consistent with terrestrial plants. The conventional radiocarbon age NZA-19380 was calculated as $389 \pm 35 \mathrm{BP}$. This conventional radiocarbon age was converted to calendrical years using the IntCal04 atmospheric curve (Reimer et al. 2004) and OxCal software (v4.0.3 Bronk Ramsey (2007); r:5). This gave the following result (Figure 5).

$68.2 \%$ probability

$\begin{array}{ll}55.7 \% & \text { AD } 1447 \text { to } 1514 \\ 12.5 \% & \text { AD } 1600 \text { to } 1617 \\ 95.4 \% \text { probability } \\ \begin{array}{ll}63.9 \% & \text { AD } 1440 \text { to } 1525 \\ 31.5 \% & \text { AD } 1557 \text { to } 1632\end{array}\end{array}$

It is unfortunate that there was a significant change in the level of ${ }^{14} \mathrm{C}$ in the atmosphere between $\mathrm{AD} 1450$ and 1650, which is readily seen in the calibration graph in Figure 
Table 2. Pohara fishhook material from low-power microscopic observation.

\begin{tabular}{ll}
\hline Hook \# & Possible identification \\
\hline 1 & Shell. This could be Alcithoe sp. or Cookia sp. \\
2 & Shell. ?sp. \\
3 & Shell. ?sp. \\
4 & Shell. The specimen has nacreous layers interspersed with conchiolin, suggesting a shell such as Hyridella sp. \\
5 & Bone. Very dense, ?sp., possibly Homo sapiens. \\
6 & Bone. Probably either whale or seal. \\
7 & Bone. Probably either whale or seal. \\
8 & Bone. Very dense, ?sp., possibly Homo sapiens. Snooding fibres present. \\
9 & Bone. Probably either whale or seal. \\
10 & Bone. Probably either whale or seal. \\
11 & Bone. Probably either whale or seal. \\
12 & Bone. Very dense, ?sp., possibly Homo sapiens calvarium. \\
13 & Bone. Probably either whale or seal. Snooding fibres present. \\
14 & Bone. Very dense, ?sp., possibly Homo sapiens. Snooding fibres present. \\
15 & Shell. With thick periostracum, ?sp. Snooding fibres present. \\
\hline
\end{tabular}

5. This is the cause of ambiguity in converting the radiocarbon years $\mathrm{BP}$ to calendrical years AD. There are two peaks, centred on AD 1465 and AD 1610. Even with the excellent standard error of \pm 35 years for the CRA, this ambiguity is unable to be resolved and reveals a fundamental weakness in using radiocarbon dating for an important portion of the pre-European period of Maori history. It is hoped that in the future alternative methods, such as electron spin resonance dating, which do not have this inherent problem will find greater application in New Zealand. ESR spectra from minute samples of human bone and teeth have been successfully used to date events within the past 1000 years (Dennison et al. 1985, 1993; Whitehead et al. 1986; Dennison and Peake 1992).

\section{Comparison with hooks elsewhere}

Two forms of hook were recognised above: four hooks with in-turned points but no shank barb, and the remaining eleven hooks with shank barbs (all the complete ones also have in-turned points). Hook 1, which we have grouped with the shank-barbed hooks, has a less pronounced protrusion from the shank than the other hooks and might not be classed as shank-barbed by some archaeologists.

Plain unbarbed U-shaped hooks with in-turned points are an old Polynesian form, found in early archaeological sites in the Society and Marquesas Islands and throughout New Zealand, although they seem to have been particularly popular in Northland and Coromandel (Davidson 1984:66-68). There is considerable variation in the exact shape and in the way the head of the shank is modified to facilitate line attachment, but forms not unlike Hooks 3, 6 and 12 at Pohara can be seen among fishhooks in early sites from Northland to Otago (e.g. Hjarno 1967:59, 61; Furey 2002:59). Hook 2, with its rather clumsy-looking in-turned point, is less easily matched elsewhere. However, it is noteworthy that in all four of these Pohara hooks, the point turns 


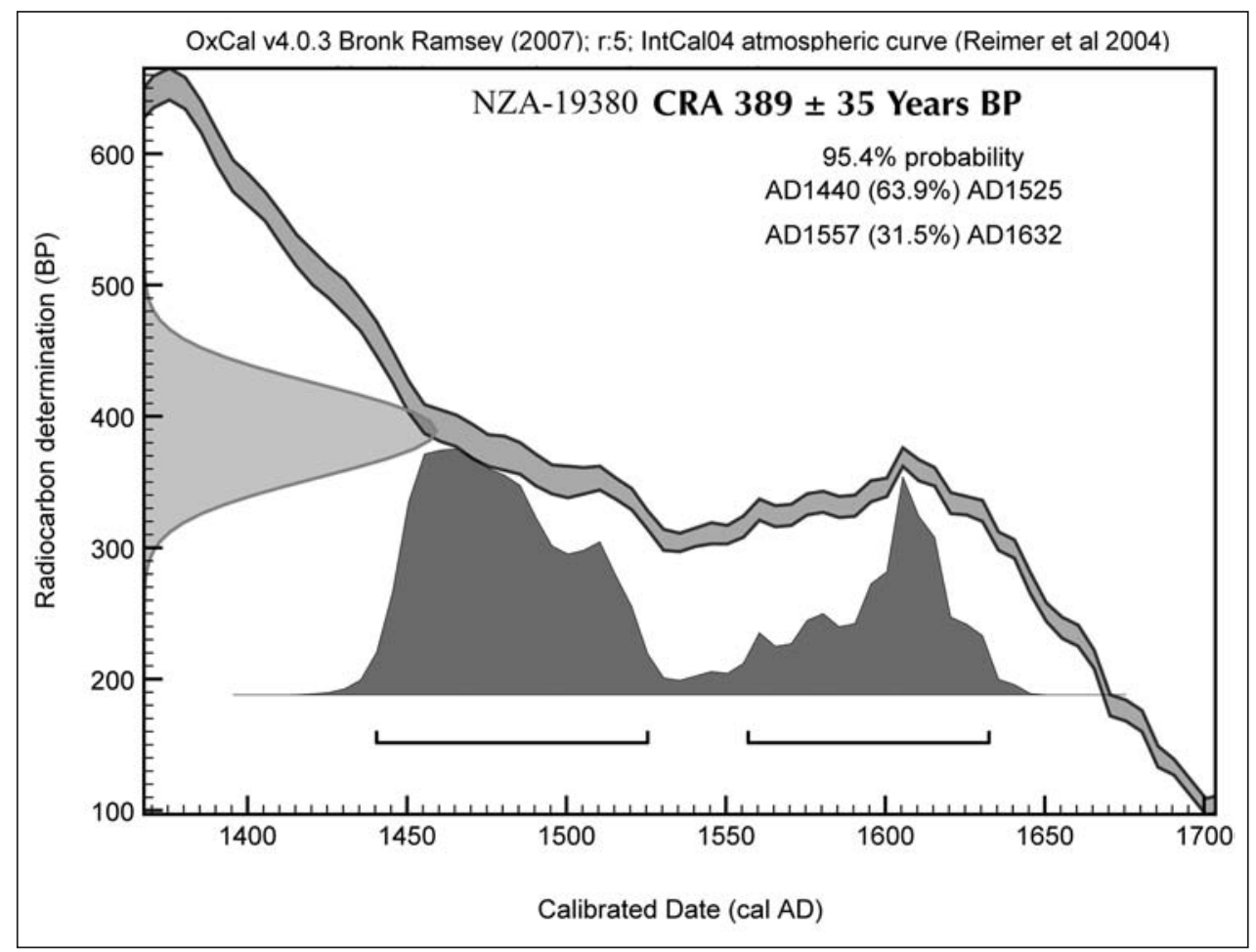

Figure 5. Calibration of the radiocarbon date for the Pohara fishhooks.

downwards far more markedly than in most examples from New Zealand. Downward-turned points do not seem to be present in early archaeological sites, but are occasionally found in later sites as far afield as Kaikoura and the Bay of Plenty (Davidson 1984:Fig. 49n, 501). Such sharply down-turned points are also seen in some tropical Pacific examples.

Shank-barbed hooks have long been recognised as a distinct form in New Zealand. Skinner pointed to comparable examples from Hawai'i and Easter Island and suggested that shankbarbed hooks were an 'old Polynesian feature' (Skinner 1942:218). He made a distinction between hooks with a projection on the inner bend of the shank leg immediately below the snood lashing knob (similar to that seen in Pohara hooks 1 and 12), which he thought might have been intended to protect the snood lashing from friction, and 'small one-piece hooks made from human bone and common on the east coast of the North Island', in which this projection did seem designed 'to assist in hooking the fish' (ibid).

Trotter discussed shank-barbed hooks as a 'well marked variety of one-piece hooks' (Trotter 1956:245), describing examples from mainland New Zealand and comparing them with hooks from the Chatham Islands, Hawai'i, Easter Island and Japan. Crosby (1966:200, 221, Fig. 66) classified shank-barbed hooks as a 'Portland Type', which she described as mostly small, wellknown ethnographically, and characterised by a gap of only 2 to $3 \mathrm{~mm}$ between barbs. Trotter and Crosby both reported occasional examples from Northland, Coromandel, Otago and Southland, but found that the main distribution was between Mahia Peninsula and Wellington, down the lower east coast of the North Island. Trotter (1956:251) correlated this distribution with Skinner's (1921) East Coast culture area.

The importance of shank-barbed hooks on the east coast of the North Island has been reinforced in several studies by Millar (nd, 1992, 1999) of well-localised private collections. Twenty-three complete examples from Portland Island (Millar 1992) are small (ranging from $24 \mathrm{~mm}$ to $30.5 \mathrm{~mm}$ long) and have gaps of no more than $2.75 \mathrm{~mm}$ between the barbs. Seventyeight percent have bait notches, and 41 percent of a larger sample, including broken hooks, have 
serrations on the outer edge. This is the form of shank-barbed hook that is sometimes found in museum collections with snoods and lines still attached (Te Papa 2004:1, 300\#10).

Shank-barbed hooks similar to those from Portland Island, described by Trotter, Crosby and Millar, were collected during James Cook's visits to New Zealand between 1769 and 1777. Several attributed to Cook's voyages are in Te Papa. Two shank-barbed hooks (Figure 6) are among 17 hooks now in the Georg August University of Göttingen (Hauser-Schäublin and Krüger 1998:300-302); they are serrated like many protohistoric hooks from New Zealand. The other 15 Göttingen hooks include an unbarbed one-piece shell hook with in-turned point, an unbarbed serrated bone hook with a small barb-like protrusion at the base of both point and shank, two different forms of trolling lure, and a variety of composite bait hooks with wooden shanks and bone points. These hooks were purchased from a London dealer, George Humphrey, in 1782 and derive from Cook's second and third voyages. The main locality for collecting Maori objects on these two voyages was Queen Charlotte Sound. Hooks were certainly collected there on June 1 and November 221773 (Forster 2000:125, 276) and probably on other occasions as well. Hooks were also acquired off the entrance to Wellington Harbour on November 2 (Forster 2000:268), near an area where elaborately notched shank-barbed hooks have been found (Beckett 1953). There were also opportunities for hooks to be acquired during trading just south of Cape Kidnappers on October 221773 (Forster 2000:265) and at Tolaga Bay in November (Beaglehole 1969:742).

The two shank-barbed hooks in Göttingen are $30 \mathrm{~mm}$ long and have narrow gaps of 1.5 $\mathrm{mm}$ and $2.3 \mathrm{~mm}$. Both are serrated. Both the snoods and the lines are noticeably thick for such small hooks. The thin line near the top of the snood lashing in Figure 6A might at first glance be mistaken for a bait line coming from the snood lashing, but it is actually the terminal strands of the main line, twisted downwards. A similar example of untwisted loose strands is more clearly seen in the second hook (Figure 6B). A shank-barbed hook illustrated by Beasley (1928:Fig. XIIA) and Trotter (1956:Fig. 5) has a thin twisted cord attached to the snood lashing

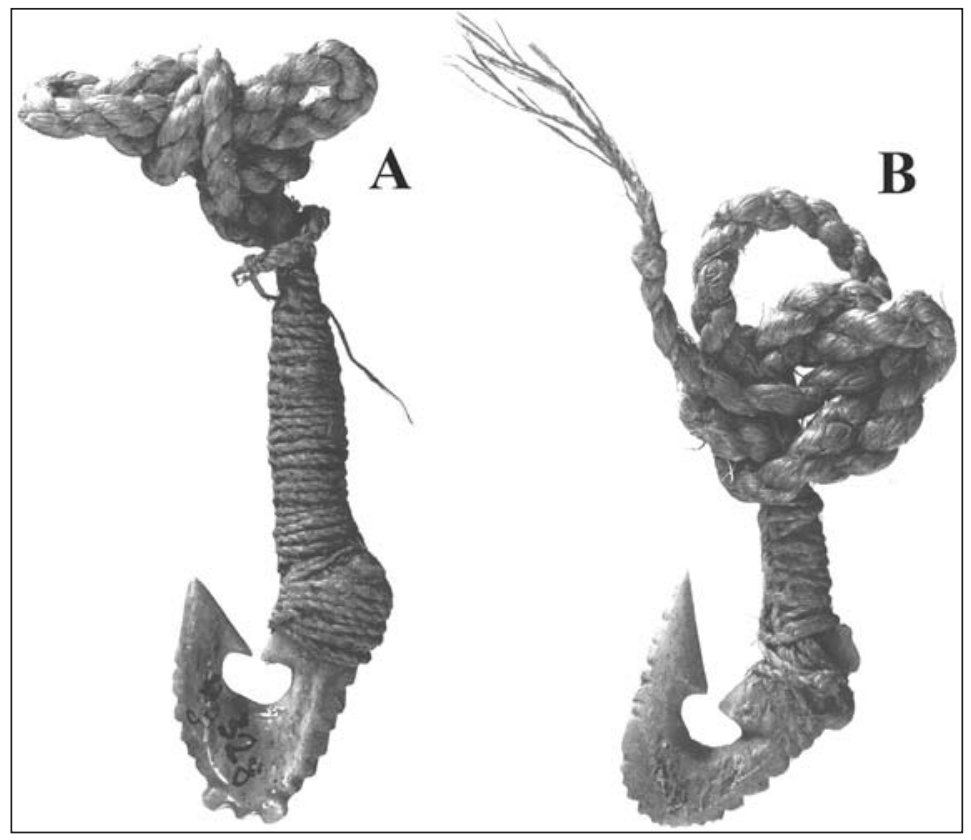

Figure 6. Two shank-barbed fishhooks collected during the visits of James Cook to New Zealand in AD 1773-1777, and now in the Institute of Cultural and Social Anthropology, Georg August University of Göttingen, catalogue numbers A: $0 z$ 328, and B: $0 z 329$ (courtesy of Gundolf Krüger). 
in addition to the main line. This appears to be a bait line. This arrangement is puzzling since the hook also has a bait notch in the bend. We know of no other ethnographic example with a similar ancillary line.

The Pohara shank-barbed hooks are somewhat larger than and differ in an important respect from the Göttingen and Te Papa examples and most of those illustrated by Trotter and Crosby. In all of the latter, the feature on the point leg is more like an inner barb, while in the Pohara hooks it is a distinctive down-turned point. The space in the centre of the hook is heartshaped in the Pohara hooks, but not in the others. However, the Pohara hooks find a striking parallel in a recently described collection from Ocean Beach, just south of Hawkes Bay. The Hamish Gordon collection now in Lindisfarne College (Millar 1999) includes bone and shell shank-barbed hooks remarkably similar to those from Pohara, differing only in the presence of serrations on most of the bone ones (Figure 7). The collection also includes unbarbed hooks with in-turned points, although these are not as sharply down-turned as the Pohara ones. In this Ocean Beach collection, the feature on the point leg of the shank-barbed hooks is an in-turned point, not an inner barb. The Ocean Beach hooks are smaller than most of the Pohara hooks, ranging in length from about $28 \mathrm{~mm}$ to $34 \mathrm{~mm}$.

Shank-barbed fishhooks from reliable archaeological contexts are extremely rare and none are well dated. There are single broken examples from Hot Water Beach and Opito on the Coromandel Peninsula, Pariwhakatau in Marlborough (Davidson 1984:fig. 50e-g) and Panau on Banks Peninsula (Jacomb 2000:67-68). Complete examples are reported from Oruarangi in the Hauraki Plains (Furey 1996:figs 339-340), Paremata near Wellington, and Murdering Beach in Otago (Davidson 1984:fig. 50h-j). The last two are thought to be of early 19th century age. The broken examples are plain; the others have serrations on the outer edges. Together, they probably date from middle pre-European to early post-contact times.

In summary, our review suggests the Pohara hooks represent a relatively early form of the shank-barbed hook in New Zealand, with down-turned point rather than inner-barbed point, lacking the serrations more common on later hooks, and being somewhat larger than the known

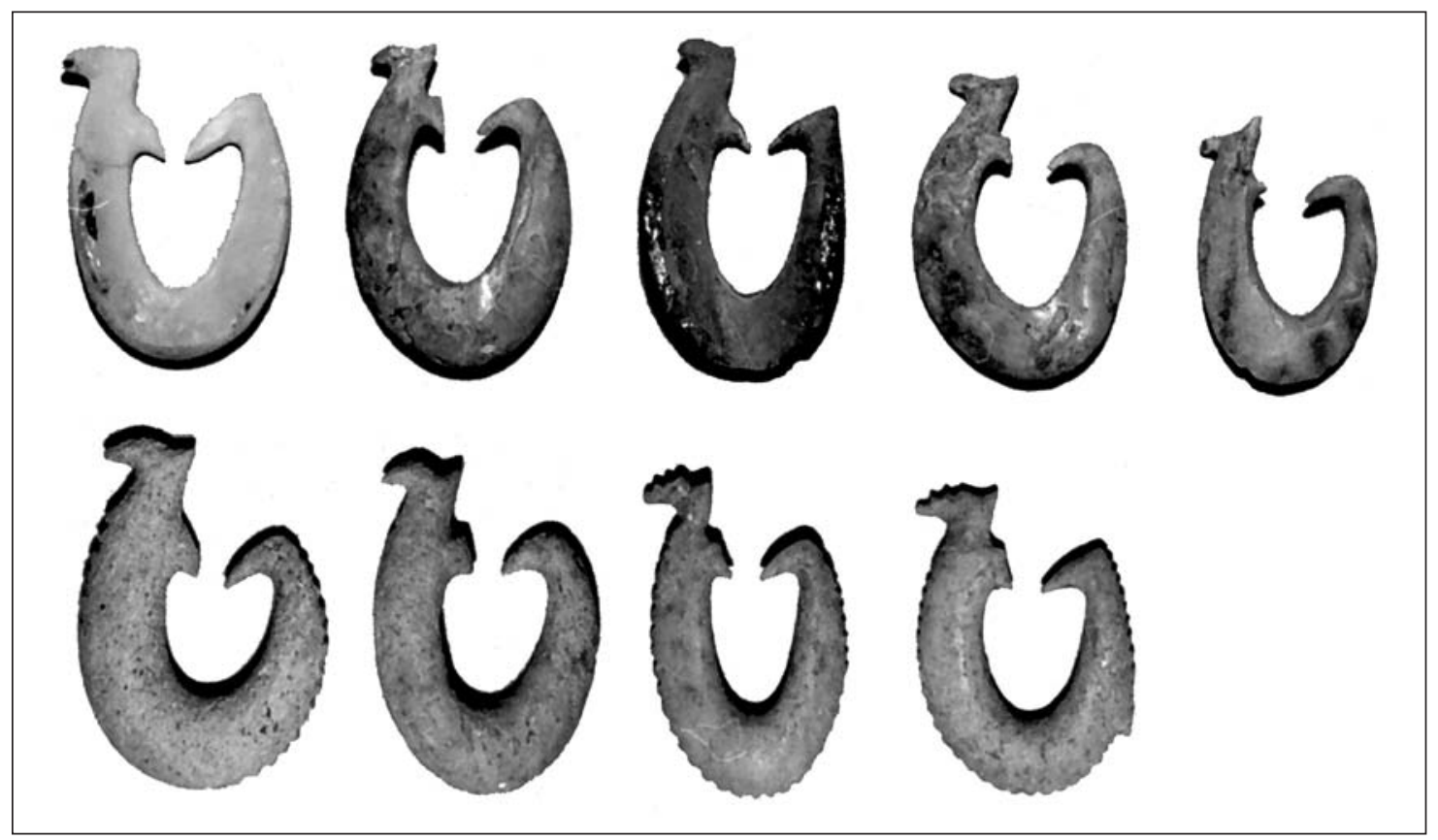

Figure 7. A selection of fishhooks from the Hamish Gordon Memorial Collection at Lindisfarne College (courtesy of Don Millar). Top row shell, bottom row bone. 
Portland Island hooks and ethnographic examples. The similarities to some hooks from Ocean Beach are very striking and raise questions about connections between the two areas.

\section{Form and function}

Classifications of fishhooks in New Zealand and the Pacific have tended to focus on form, with less attention to function. Discussions of hanging baited hooks often distinguish between jabbing hooks and rotating hooks, which are thought to function differently. Nordhoff (1930:156) first described the action of rotating hooks used in still-fishing (rather than trolling) for albacore in the Society Islands. Reinman (1970:56) suggested particular types of hooks were intended to exploit particular environments and the fish that inhabit them. He emphasised the interrelationship between structural variables (primarily the effect of material on form), functional variables (particularly how the hook is presented to the fish to maximise penetration and prevent escape) and ecological variables (such as fish size, behaviour and habitat). More recently, Allen (1996) endeavoured to distinguish stylistic and functional variables in East Polynesian hooks, and found that functional aspects of hook morphology are still poorly understood. Most studies, however, have concentrated on form without considering what kinds of fish were targeted and how the hooks actually captured and held them. The Pohara hooks, with their tiny gaps between point and shank, highlight these issues.

Previous writers have commented on the narrow gap between point and shank in Maori fishhooks in general, and in the shank-barbed hooks in particular (Trotter 1956:245; Crosby 1966:221). Anell (1955:107-108), in a wide-ranging review of fishing in Oceania, suggested Maori hooks with double inner barb (his term for shank-barbed hooks) might have been ornamental rather than functional, whereas Trotter (1956:246) considered they were mostly functional. It is possible the single known example in pounamu or greenstone (Oldman 2004:Plate 20 no. 97) was ornamental or ceremonial, because of the value of the raw material and its frequent use in ornaments, although in form it is identical to the many small bone examples attributed to the Portland Island area. Unfortunately, it is part of the Oldman Collection, repatriated to New Zealand in 1948, and its original provenance is unknown.

There is no reason to doubt that the Pohara hooks were functional. One of us (Leach 2006: 117-130) has considered the question of the function of Maori one-piece hooks in detail, drawing on studies of hook function in relation to fish behaviour in other parts of the world. It has been proposed that Maori hooks with narrow gaps were rotating hooks, which functioned in the following way (Figure 8):

According to this theory the fish does the catching, not the fisherman. ... at A, the fish approaches the hook (bait not shown). Many fish are accustomed to eating extraneous matter, such as fragments of shell, with their food and a hook with no projection could easily be swallowed without discomfort (shown at B). If the line is tugged at this point, the hook would come out of the fish's mouth, but if left alone, the fish will swim away, carrying the line along its side (shown at C). The line will eventually become taut, and begin to pull the hook out of the fish's mouth. At first, the force on the hook is towards the front of the fish, but the instant the shank becomes clear of the mouth the direction of the force changes towards the rear of the fish, causing it to rotate rapidly. It will come to rest with the shank of the hook lying outside the jaw, and the point lying inside the jaw (shown at D). From this stage on the fish cannot escape. If the line is now tugged or the fish tries to change direction, the hook will rotate in the mouth, acting as a lever, and the point will penetrate behind the jawbone. In theory, to a certain extent, the narrower the gap between the shank and the point, the better. In addition, the hook rotates more effectively if the shank is the same length as the leg on which the point occurs. (Leach 2006:118-119) 


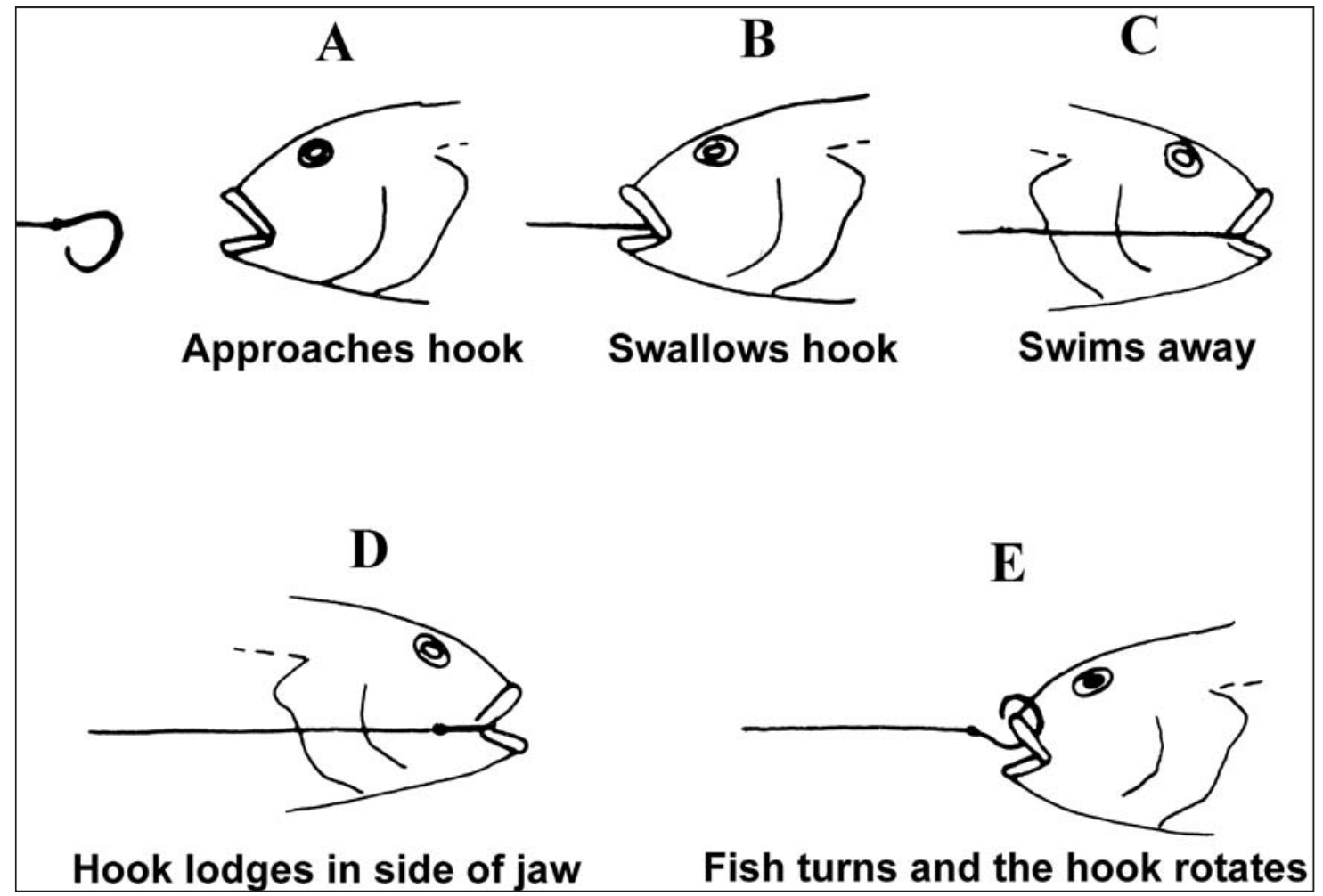

Figure 8. A theory of how the rotating hook might work (from Leach 2006:118).

It was stressed that this is a theory, which needs to be tested by observations of real fish, using replica hooks. But would this theory apply to shank-barbed hooks with tiny gaps, such as the Pohara hooks? Elsewhere in Polynesia, shank-barbed fishhooks are best documented from Hawai'i. Emory et al. (1959:42) found shank-barbed hooks in both early and late contexts in archaeological sites at South Point on the island of Hawai'i and classified them (without discussing the issue) as jabbing hooks. In Sinoto's revised classification of Hawaiian hooks, shankbarbed hooks are variously considered to be jabbing or rotating hooks, depending on whether or not the point is in-turned (Sinoto 1991:100). Although this is a functional classification, it is not based on any experimental or ethnographic evidence. In this respect, it is worth quoting comments on this subject by Elsdon Best as follows:

The shape of native-made fish-hooks often surprises observers, in that the point is so close to the shank, but old natives have assured me that such hooks were the most effective, and decidedly superior to the wide-mouthed ones for taking certain fish (Best 1977:43).... The somewhat slender hooks employed in taking albatross were much more open than most fish-hooks, and the shanks thereof were often adorned with finely executed carved designs (ibid:45).

Clearly, the size of the point gap was of considerable functional importance. The point gaps of the two hooks illustrated in Figure 6 are especially small, at only $1.5 \mathrm{~mm}$ and $2.3 \mathrm{~mm}$, and the 10 Pohara specimens with shank-barb average a mere $2.39 \mathrm{~mm}$, causing one to wonder what part of the fish anatomy could possibly pass through such a tiny entrance? One possibility is one of the bones in the gill arch of fish. The bones that make up the branchial arch, while flexible, are strongly held together and thin enough to pass through a narrow gap in a fishhook, such as those illustrated in Figures 4, 6 and 7. When fish identify non-food debris during feeding, they can spit this out either through the mouth or through the gill arch. Ejection of debris through the gill arch has been observed with snapper (Pagrus auratus) in aquaria (Larry Paul pers comm. 
2007), and this species is one of the most common in Golden Bay. The particular elements in the branchial arch most likely to have been caught by such a hook passing out through the gill arch would be one of the long thin bones known as the epibranchial and ceratobranchial elements. European fishermen are used to baiting their hooks with the bait attached to the point leg. However, bait could be attached to the bait line at some distance below the hook, so that when the fish swallowed the bait, the small hook would remain unswallowed in the back of the throat. If the main line was slack, the hook could be ejected through the gill arch, and if the fish pulled against the line, the epibranchial or ceratobranchial could easily pass through the tiny gap in the hook and be inextricably captured. An interesting feature of a hook functioning in the manner described is that a very small hook could catch a very large fish, and in fact it would be an advantage for such a hook to be as small as possible. We might now look at the two hooks illustrated in Figure 6 with a somewhat different perspective. It will be observed that the snood lashing is very large and strong and seems out of character with the small size of the hook itself. The line attached to the hook is also very thick and strong, when we might have expected a delicate line for these small hooks. On the other hand, if these small hooks were really designed for capturing large, strong fish, these features would make a lot more sense.

The idea that these Pohaha shank-barbed hooks with such a narrow gap were designed for capturing large fish in the bones of the gill arch is only a hypothesis at the moment, but it certainly deserves testing. This would require making replicas, baiting them in various ways, and observing the behaviour of different species of fish using scuba equipment or in an aquarium.

One final point - all of these hooks with such a narrow gap, forged by the in-curved point and the shank barb and displaying this heart-shaped interior mentioned earlier, display a feature reminiscent of the 'non-return' principle present in numerous types of fishing equipment (Brandt 1984:166ff.). This occurs when there is a barrier with an in-curved entrance that permits fish to enter a trap but not exit. The principle is well known in many forms of Maori and Polynesian fishing technology, from eel traps (hinaki) to fish weirs. Thus characterised, the pre-European Maori fisherman might see these hooks as symbolically similar to other forms of fish trap.

Whatever the reality, the owner of the Pohara cache obviously believed that his fishhooks, made of various materials and with subtle variations in form, would catch fish.

The question of what species of fish these hooks might have been designed to catch, or been most effective in catching, is not easy to answer. At best, only very broad guidelines can be given. For example, one-piece baited hooks are quite effective in catching pelagic predators, such as kahawai (Arripus trutta) and barracouta (Thyrsites atun), which are instantly attracted to lures, although flashing red-coloured lures are more effective. Conversely, lure hooks are known to catch groper (Polyprion oxygeneios) and even stargazers (Kathetostoma giganteum) hugging the bottom. One possible clue to species caught by these hooks might be the common species in the vicinity of Pohara, such as snapper (Pagrus auratus) and seasonally abundant kahawai. However, this is a weak interpretation because the owner of the hooks may have used them primarily at a more distant rocky-shore location where blue cod (Parapercis colias) are abundant. Finally, the composition of nearby midden might be used to help interpret the species caught with such hooks. Unfortunately, this is also highly questionable, as detailed research on this matter with middens and large collections of hooks on small Pacific islands has shown (Leach and Davidson 1988; Davidson and Leach 1996). All these forms of indirect argument, from cause to effect and then back again, to help identify species from form are prone to such difficulties. It is more sensible simply to accept this problem and pay greater attention to interpretations that are on safer ground. 


\section{Discussion}

A find such as the Pohara cache offers a unique glimpse into the past. It is almost certainly the collection of a single fisherman, who hid his hooks in a safe place, expecting to return and reclaim them, but failed to do so, for reasons we can never know.

The cache represents fishing gear last used by one person at one time and place. Wherever the fisherman lived, he probably last used his hooks in the eastern part of Mohua and expected to do so again. This goes some way towards meeting Reinman's ecological variable. We have already discussed the possible way these hooks functioned. Experiments with replicas may in future confirm how they functioned, and assist in understanding the fish targeted. In this case, the influence of material on form appears to be slight. Very similar forms could be rendered in more than one kind of shell and at least two different kinds of bone. This use of different materials may reflect the fisherman's beliefs about what was appropriate for different kinds of fish or different fishing conditions, or even the need to conform to ritual observance.

Archaeologists try to describe and classify fishhooks using assemblages consisting mostly of broken fragments of hooks that had probably been used by a variety of different fishermen over a period of uncertain duration. In the very large collection of 1016 hooks from Houhora in Northland, only 31 were intact (Furey 2002:56). Ethnographic collections are more likely to include complete hooks belonging to one person, or deriving from one time or place, but the contextual information is seldom good enough to be sure of this.

The Pohara hooks encompass variations in detail which could be mistaken by archaeologists for regional or chronological markers. There is a range in shape, from an almost V (Hook 3) to several perfect U-shapes. Most hooks are symmetrical, but Hook 5 is not. There are several different head types. The head is a favourite feature in archaeological classifications because it is variable (Sinoto 1962; Hjarno 1967; Allen 1996; Furey 2002). Allen (1996:113) suggests these variations are stylistic rather than functional and some variants, at least, may reflect ancestral relationships and patterns of interaction. The Pohara hooks provide a warning about attempting to interpret variations in head form. Any suggestion that such variations may be functional or stylistic features with regional or chronological meaning is fraught with problems.

Some of the Pohara hooks have 'bait notches' and others do not; on several, the bait notch is like a tiny non-functional barb. Only one has a small series of notches that could be a precursor to the more extensive notching seen on many shank-barbed hooks elsewhere. The single most defining feature of these hooks is the sharply down-turned point, which is present on all of them, although it is least pronounced on Hooks and 3 and 6. Unfortunately, points are very often missing from the hooks archaeologists usually have to deal with.

Nothing is known ethnographically about the making of fishhooks. Were there specialist makers or did most fishermen make their own? Are the Pohara hooks the work of one maker (either their owner, or a specialist from whom he obtained them), or are they the work of several different makers? In the latter case, the makers obviously would have shared a conviction that sharply down-turned points were effective.

The Pohara cache can be compared with another fisherman's kit found at Jackson Bay in Westland (Leach 2007). This consists of 38 bone points from composite hooks - 26 lure points and 12 points for composite bait hooks that would have had wooden shanks. These items are completely different in form from the Pohara hooks, and most of them are parts of trolling hooks, rather than hanging baited hooks. The Jackson Bay cache is also surprising in that it contains nine points of a form unknown in the South Island, and previously described from the site of Oruarangi in the Hauraki Plains of the North Island. Both of these caches, found on 
or towards the South Island west coast, seem to point to North Island connections. Maori oral histories give some insights into the web of interconnections between the islands.

The complex sequence of tribal occupation in Te Tau Ihu (the top of the South Island), including Mohua, has been reviewed in detail by Mitchell and Mitchell (2004:43-98), who describe movements into the area from both the east and west coasts of the North Island. At the time of Tasman's brief and unhappy visit to Mohua in AD 1642, Mohua was part of the region occupied by Ngati Tumatakokiri, a tribe said to have moved there from the central North Island via Whanganui (Mitchell and Mitchell 2004:74). Ngati Tumatakokiri was, however, a Kurahaupo tribe, a tribal ancestor Tumatakokiri being a son of Whatonga (Mitchell and Mitchell 2004:59). Kurahaupo tribes occupied much of the southern North Island, including Skinner's (1921) East Coast culture area, as well as moving progressively into the South Island. Connections and movements between the east coast of the North Island and the top of the South Island are well documented (e.g. O’Regan 1987). The similarity in fishhooks as far as apart as Mohua and Ocean Beach may not, therefore, be so surprising.

\section{Conclusions}

The Pohara cache is a unique collection of fishhooks, representing one man's kit at one point in time, and used at one particular place. Although the hooks show some variability in form, they are characterised by the sharply down-turned point of all examples and the narrow gap between point and shank, which is most marked in the 11 shank-barbed examples. How these hooks actually functioned remains unknown. Hypotheses on this issue can only be tested by direct observations using replicas.

The radiocarbon date places the hooks in the early to middle part of the pre-European sequence in New Zealand, earlier than the extensively serrated examples of shank-barbed hooks from Portland Island and other places, some of which are known to date to the 18th and early 19th centuries. There are striking similarities to one undated collection of hooks from Ocean Beach, just south of Hawkes Bay, although many of these carry the serrations which are present on the later examples from Portland Island and elsewhere, but not on the Pohara hooks.

The Pohara cache has probably doubled the number of known examples of shank-barbed hooks from secure contexts outside the previously known main distribution from Mahia to Wellington. This suggests how much remains to be learned about pre-European Maori fishhooks.

\section{Endnote}

1. The term 'snood' refers to the short line connecting the hook to the main line; 'snood lashing' refers to the attachment of the snood to the hook. Snood lashings on some Polynesian hooks were very complex (Hiroa 1957:339-341).

\section{Acknowledgements}

We are most grateful to Chris Hill and Manawhenua ki Mohua for the opportunity to study this important collection and for their interest and encouragement. We would also like to thank the Nelson Provincial Museum for access to the collection. Steve Bagley (Department 
of Conservation, Nelson) took the photographs of the site, and Rita Larje drew the hooks. Hamish Campbell (GNS Science) and Keith Miller (Holcim [New Zealand] Ltd) provided information on the limestone, and Larry Paul (formerly of NIWA) provided useful comments on fish behaviour in aquaria. The radiocarbon date was run free of charge for Mana Whenua ki Mohua by the Rafter Laboratory, GNS, through the good offices of Rodger Sparks. Rod Wallace (Auckland University) and Catherine Smith and Debra Carr (Otago University) examined the fibres. Gundolf Krüger (Georg August University of Göttingen) sent us measurements and photographs of the hooks in Göttingen. Last but not least, Don Millar (Honorary Curator of New Zealand Archaeology, Hawke's Bay Cultural Trust) shared his knowledge of Hawke's Bay collections of fishhooks, and was as helpful to us now as he was to Atholl Anderson more than 40 years ago.

\section{References}

Allen, M.S. 1996. Style and function in East Polynesian fish-hooks. Antiquity 70:97-116.

Anderson, A.J. 1966. Maori Occupation Sites in Back Beach Deposits around Tasman Bay. Unpublished MA thesis (Geography), University of Canterbury.

Anell, B. 1955. Contribution to the History of Fishing in the Southern Seas. Studia Ethnographica Upsaliensia IX.

Beaglehole, J.C. (ed) 1969. The Voyage of the Resolution and Adventure 1772-1775. Cambridge: Cambridge University Press for the Hakluyt Society.

Beasley, H.G. 1928. Pacific Island Records: Fishhooks. London: Seeley and Service.

Beckett, P. 1953. Two fish hook parts from a midden in Wellington. Journal of the Polynesian Society 62(2):196.

Best, E. 1977. Fishing Methods and Devices of the Maori. Dominion Museum Bulletin 12. Wellington: Government Printer [Repaginated reprint of 1929 edition].

Brandt, A. von. 1984. Fish catching methods of the world. Farnham: Fishing News Books.

Bronk Ramsey, C. 2007. Deposition models for chronological records. Quaternary Science Reviews (INTIMATE special issue). In press.

Colenso, W. 1875. On the geographic and economic botany of the North Island of New Zealand. Transactions and Proceedings of the New Zealand Institute, 1868, Vol. 1:233-283.

Crosby. E.B.V. 1966. Maori Fishing Gear: A study of the development of Maori fishing gear, particularly in the North Island. Unpublished MA thesis, Anthropology, University of Auckland.

Davidson, J.M. 1984 The Prehistory of New Zealand. Auckland: Longman Paul.

Davidson, J.M. and B.F. Leach 1996. Fishing on Nukuoro Atoll: Ethnographic and archaeological viewpoints. In M. Julien, M. Orliac, and C. Orliac (eds), Mémoire de Pierre, Mémoire D'Homme: Tradition et Archéologie en Océanie. Hommage à José Garanger, pp.184-202. Paris: Publication de la Sorbonne.

Dennison, K.J. and B.M. Peake 1992. ESR bone dating in New Zealand. Proceedings of the 6th International Specialist Seminar on Thermoluminescence and Electron Spin Resonance Dating. Clermond-Ferrand, France. 2-6 July, 1990. Quaternary Science Reviews 11:251-255.

Dennison, K.J., P. Houghton, B.F. Leach and B.M. Peake 1985. Sample preparation and instrumental aspects of EPR dating of New Zealand human bone. In M. Ikeya and T. Miki (eds), ESR dating and dosimetery, pp. 341-352. Tokyo: Ionics.

Dennison, K.J., A.D. Oduwole and K.D. Sales 1993. Some ESR observations on bone, tooth enamel and eggshell. Proceedings of the 3rd International Symposium on ESR Dosimetry and Applications. Gaithersburg, Maryland, 14-18 October, 1991. Applied Radiation and Isotopes 44:261-266. 
Emory, K.P., W.J. Bonk, and Y.H. Sinoto 1959. Hawaiian Archaeology: Fishhooks. Bernice P. Bishop Museum Special Publication 1959, Honolulu, Bishop Museum Press.

Forster, G. 2004. A Voyage Round the World. 2 Vols. Edited by N. Thomas and O. Berghof. Honolulu: University of Hawai'i Press.

Furey, L. 1996. Oruarangi: The Archaeology and Material Culture of a Hauraki Pa. Auckland Institute and Museum Bulletin 17.

Furey, L. 2002. Houhora: A Fourteenth Century Maori Village in Northland. Auckland Museum Bulletin 19.

Goulding, J.H. 1971. Identification of archaeological and ethnological specimens of fibre-plant material used by the Maori. Records of the Auckland Institute and Museum 8:57-101.

Hauser-Schäublin, B. and G. Krüger (eds) 1998. James Cook: Gifts and Treasures from the South Seas. Munich and New York: Prestel.

Hiroa, Te Rangi (P.H. Buck) 1950. The Coming of the Maori. Wellington: Maori Purposes Fund Board.

Hiroa, Te Rangi (P.H. Buck) 1957. Arts and Crafts of Hawaii. Bernice P. Bishop Museum Special Publication 45. Honolulu: Bishop Museum Press.

Hjarno, J. 1967. Maori fish-hooks in southern New Zealand. Records of the Otago Museum Anthropology $3: 1-63$.

Jacomb, C. 2000. Panau: The Archaeology of a Banks Peninsula Maori Village. Canterbury Museum Bulletin 9.

Leach, F. 2006. Fishing in Pre-European New Zealand. New Zealand Journal of Archaeology Special Publication, Wellington.

Leach, F. 2007. A cache of fishhooks from Serendipity Cave, Jackson Bay, New Zealand. In A. Anderson, K. Green and F. Leach (eds), Vastly Ingenious: The Archaeology of Pacific Material Culture, pp. 79-95. Dunedin: Otago University Press.

Leach, B.F. and J.M. Davidson 1988. The quest for the rainbow runner: prehistoric fishing on Kapingamarangi and Nukuoro atolls, Micronesia. Micronesica 21 (1, 2):1-22.

Millar, D. 1992. Maori Artifacts from Waikawa Hawke’s Bay. Unpublished report to the Hawke’s Bay Museum.

Millar, D. 1999. Hamish Gordon Memorial Collection of Maori Artefacts - Lindisfarne College. Unpublished report, Hawke's Bay Cultural Trust.

Millar, D. nd. Taonga Waipuka. A Collection of Artefacts Mainly from Ocean Beach, Hawke's Bay. Unpublished report to Hawke's Bay Museum.

Mitchell, H. and Mitchell, J. 2004. Te Tau Ihu o Te Waka. A History of Maori of Nelson and Marlborough. Volume 1. Te Tangata me Te Whenua - The People and the Land. Wellington : Huia in association with Wakatu Incorporation.

Nordhoff, C. 1930. Notes on the off-shore fishing of the Society Islands. Journal of the Polynesian Society 39:137-173, 221-262, 380.

Oldman, W.O. 2004. The Oldman Collection of Maori Artifacts. Polynesian Society Memoir 14, Auckland.

O'Regan, S. 1987. Queen Charlotte Sound: Aspects of Maori traditional history. In G. Barrett (ed), Queen Charlotte Sound, New Zealand: the Traditional and European Records, 1820, pp. 139-158. Ottawa: Carleton University Press.

Rattenbury, M.S., R.A. Cooper and M.R. Johnston 1998. Geology of the Nelson area. Institute of Geological and Nuclear Sciences 1:250,000 Geological Map 9.

Reimer, P.J., et al. 2004. IntCal04 terrestrial radiocarbon age calibration, 0-26 cal kyr BP. Radiocarbon 46(3):1029-1058.

Reinman, F.M. 1970. Fishhook variability: Implications for the history and distribution of fishing gear in Oceania. In R.C. Green and M. Kelly (eds), Studies in Oceanic Culture History Volume 1, pp. 47-59. Pacific Anthropological Records 11. Department of Anthropology, Bernice P. Bishop Museum.

Sinoto, Y.H. 1962. Chronology of Hawaiian fishhooks. Journal of the Polynesian Society 71(2):162-166. 
Sinoto, Y.H. 1991. A revised system for the classification and coding of Hawaiian fishhooks. Bishop Museum Occasional Papers 31:85-105.

Skinner, H.D. 1921. Culture areas in New Zealand. Journal of the Polynesian Society 30:70-78.

Skinner, H.D. 1942. A classification of the fish-hooks of Murihiku with notes on allied forms from other parts of Polynesia. Journal of the Polynesian Society 51(3):208-221, (4):256-286.

Te Papa 2004. Icons Nga Taonga from the Museum of New Zealand Te Papa Tongarewa. Wellington: Te Papa Press.

Trotter, M.M. 1956. Maori shank barbed fish-hooks. Journal of the Polynesian Society 65(3):245-252.

Whitehead, N.E., S.D. Devine and B.F. Leach 1986. Electron spin resonance dating of human teeth from the Namu burial ground, Taumako, Solomon Islands. New Zealand Journal of Geology and Geophysics 29:359-361. 